\title{
ASSOCIATION OF THE MTHFR C677T, FACTOR V (LEIDEN) G1961A AND PROTHROMBIN G20210A GENE MUTATIONS WITH RECURRENT SPONTANEOUS ABORATION (RSA) IN DUHOK PROVINCE
}

\author{
Shaima S. Mohammed ${ }^{\mathrm{a}, *}$, Rana A. Al-Timimy ${ }^{\mathrm{a}}$, Jinan N. Hasan ${ }^{\mathrm{b}}$ and Najat T. Mahmood ${ }^{\mathrm{a}}$ \\ a Scientific Research Centre, College of Science, University of Duhok, Kurdistan Region, Iraq - (shaima.mohammed@uod.ac) \\ ${ }^{\mathrm{b}}$ Duhok Polytechnic University, Kurdistan Region, Iraq.
}

\begin{abstract}
:
Genetic causes of thrombophilia have been suggested as a possible cause of recurrent pregnancy loss (RPL). Fifty female patients aged between 21- 40 years and experienced at least two times early pregnancy loss were enrolled in the current study. Blood samples were aspirated, infectious (TORCH), hormonal (gonadotrophines, steroids, and thyroid hormones), ultrasonic, and serological (anti-lupus and anti-phospholipid antibodies) evaluations were conducted to exclude any individual candidate who had been suspected to have causes of early pregnancy loss rather than the genetic attribute. DNA from each particular sample was extracted by components of (FVL-PTH and MTHFR)StripAssay ${ }^{\circledR}$ A kit Vienna Lab Diagnostics GmbH, Vienna, Austria).this kit includes three steps: (1) DNA isolation, (2) Multiplex PCR amplification was performed by using biotinylated primers, for detecting different mutations in the three genes of interest (FVL-PTH and MTHFR) (3) Hybridization of amplification products to a test strip containing allele-specific oligonucleotide probes immobilized as an array of parallel lines. The results revealed that 24 samples out of 50 had MTHFR C677T mutations while 2 samples only had FV (G1691A) mutation while prothrombin mutation (G20210A) has not been detected. In conclusion: genetic mutation had significant impact in patients suffered recurrent pregnancy loss.
\end{abstract}

KEYWORDS: Recurrent pregnancy loss, Thrombophilia, MTHFR (C677T), FV (G1691A), Prothrombin (G20210A) gene mutations.

\section{INTRODUCTION}

Thrombophilias are inherited or acquired conditions that predispose an individual to thromboembolism (Dong et al., 2014). In most cases, the patients remain asymptomatic, until a secondary hypercoagulable state like pregnancy, triggers off a sequence of clotting activities at the placental vasculature, resulting in thrombosis with eventual pregnancy loss (Thiruchelvam and Sekaran, 2010).

Pregnancy is hypercoagulable state. It has been found that thrombophilia is tightly linked to the severe pregnancy complications such as spontaneous loss of the fetus during the early stages of pregnancy, preeclampsia, intrauterine growth restriction, placental abruption, and stillbirth, occurring mostly during later stages of gestation (Kujovich, 2011).

Thrombophilias can be inherited (hereditary), acquired (not inherited), or both. Hereditary thrombophilia is caused by gene mutations that are passed from parents to their offspring. Gene mutations that are involved in many factors which take part in the coagulation system and other factors that maintain the normal fluidity of the blood in the vessel may cause thrombophilia by increasing tendency to thrombosis (Gaziet al., 2012).

Three common inherited thrombophilia markers, namely Factor V Leiden (FVL G1691A), Prothrombin (PTH G20210A), and Methylene tetrahydrofolatereductase (MTHFR) C677T are candidate genes for venous thromboembolism (VTE) (Neamatzadehet al., 2016). Various hypotheses were proposed to explain the role of the thrombophilic genes polymorphisms such as MTHFR C677T, MTHFR A1298C, Prothrombin G20210A, FVL G1691A, and PAI-1 4G/5G in RPL (López-Jiménez et al., 2016). A large number of studies have investigated the association between the thrombophilia gene polymorphisms and RPL susceptibility. However, the results were inconsistent or inconclusive, presumably due to the small sample size in these published studies (Farahmandet al., 2015).

Acquired thrombophilia's are due to increased levels of certain clotting substances in the blood or special proteins called antibodies which may also lead to clotting. These include the anti-phospholipid syndrome (APS), an acquired autoimmune condition, is characterized by the presence of certain features and circulating antibodies. It is defined as the presence of lupus anticoagulant (LAC) and/or anticardiolipin antibodies (ACL) with recurrent miscarriage (RM), thrombosis, preeclampsia, intrauterine growth restriction (IUGR) and placental abruption. The most specific clinical features are thrombosis (both venous and arterial thrombosis), RM and fetalloss in the second and third trimester and autoimmune thrombocytopenia (Sahet al., 2018). Recurrent miscarriage, defined as the spontaneous loss of two or more consecutive intra-uterine pregnancies with the same partner before 20 weeks' gestation, is known to affect $0.5-2 \%$ of pregnant women (McPherson, E. (2016).

The aim of the present work was to study the association between common mutations of factor V (G1691A) (Leiden), Prothrombin (G20210A) as well as MTHFR (C677T) gene and early pregnancy loss in women in Duhok province.

\footnotetext{
* Corresponding author

This is an open access under a CC BY-NC-SA 4.0 license (https://creativecommons.org/licenses/by-nc-sa/4.0/)
} 


\section{MATERIALS AND METHODS}

\subsection{Patients inclusion criteria}

Fifty patients aged between 21-40 years who attended the outpatient clinic of the Obstetrics and Gynecology hospital in Duhok province from June to December 2017 were selected for the current study. All candidates were not pregnant, with history of recurrent early pregnancy loss (at least two excluded through specific diagnostic tests. Screening for antitoxoplasma, rubella, cytomegalovirus, and herpes virus II antibodies (collectively known as TORCH) was performed according to Remingotonet al., (2004) to rule out any possible association between early pregnancy loss and those infectious agents. Each individual patient was subjected to threedimensional ultrasound examination to look for any kind of congenital anomaly that might interfere with normal gestation. Patients' hormonal profiles were also investigated by immunofluorescence technique (Vidas ${ }^{\circledR}$ ) to eliminate cases of luteal insufficiency, polycystic ovarian diseases, and thyroid dysfunction; hormones included were steroids (Estrogen, progesterone, and testosterone), gonadotropines (follicle stimulating hormone and luteinizing hormone), prolactin, thyroid stimulating hormone and free $\mathrm{T} 4$, individuals who had abnormal profile and/or profiles were omitted. Antiphospholipid and anti-lupus serum antibodies were also evaluated as per (Harris et al., 1983) and when they were elevated, the patients were excluded. Finally, any particular patient who had a history of thrombosis was excluded as well.

\subsection{Extraction of DNA and Amplification (PCR)}

DNA was extracted by components of (FVL-PTH and MTHFR) StripAssay ${ }^{\circledR}$ A kit Vienna Lab Diagnostics GmbH, Vienna, Austria). The assay covered three common gene mutations, they have a relation with thrombophilia. One hundred microliters of EDTA-blood were used to extract DNA. Spectrophotometric measurements (nano drop) were used to confirm the concentration and the purity of DNA (Al Husseiniet al., 2010).

Multiplex PCR amplification reaction mixture was prepared by adding sequence specific biotinylated primers for detecting different mutations in the three genes (FVL-PTH and MTHFR). The amplification conditions were initial denaturation at $94^{\circ} \mathrm{C}$ for 2 minutes, followed by 35 cycles of denaturation at $94^{\circ} \mathrm{C}$ for 15 seconds, annealing at $58^{\circ} \mathrm{C}$ for 30 seconds and an extension step at $72^{\circ} \mathrm{C}$ for 30 seconds. The product of the amplification was analyzed by gel electrophoresis. Five microliters of each product and 2686bp DNA ladder was separated on $1.5 \%$ agarose gel. Reverse hybridization of amplification products: The amplified products were selectively hybridized to strip Assay "Viennalab. Diagnostika GmbH" which contained allelespecific oligonucleotide probes (wild and mutant specific) immobilized as an array of parallel lines and the bound biotinylated sequences were detected using streptavidinalkaline phosphatase and color substrates (Figure 2). Ten microliters of each amplification product were used in the typing trays with one milliliter hybridization buffer added to a test strip with orbital shaking at $45^{\circ} \mathrm{C}$ for 30 minutes at $50 \mathrm{rpm}$, washing was finally performed at $45^{\circ} \mathrm{C}$ with shaking.

\subsection{Identification of the hybridized products}

Detection of specifically bound mutant and wild type alleles was performed by visible enzymatic color reaction. For each test strip, one milliliter conjugate solution (contains streptavidin-alkaline phosphatase) was added and incubated for 15 minutes at room temperature. After that one millilitercolor developer (contains Nitro Blue Tetrazolium (NBT) and 5bromo-4- chloro-3- indolyl phosphate) was added and incubated for 15 minutes at room temperature in the dark on orbital shaker.

\section{RESULTS}

Figure 1 indicated that all affected individuals had PCR profiles pointing to successful amplifications and that this manifestation clearly denoted the existence of specific mutation within these samples.

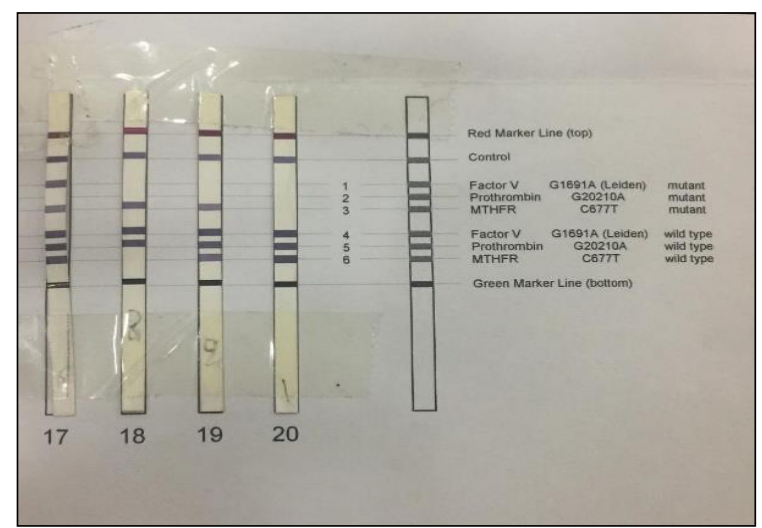

Figure 1. PCR product of FV-PTH-MTHFR genes. Lane 1-3 contain bands of $133,156,180$ bp respectively representing successful amplification in three samples; final lane to the right stands for molecular weight marker of $2686 \mathrm{bp}$. Bands run on $1.5 \%$ agarose gel.

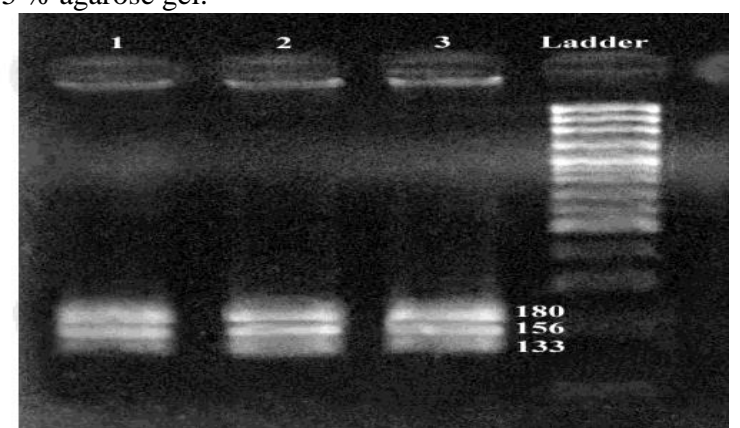

Figure 2. Design of FV-PTH-MTHFR strip assay test utilized in the present work.

The results of the present study showed that all the fifty patients tested negative for each particular test of the TORCH group; as well as ultrasonic evaluation of the enrolled individuals emphasized the normal structure of their genital systems. Hormonal profiles of each candidate patient were also within normal ranges. Moreover, anti-phospholipid and anti-lupus antibodies were not detected within the sera of the selected individuals thus they were considered negative for these two specific tests as well.

The results of the present work showed that out of fifty patients, twenty-four patients (48\%) had MTHFR (C677T) mutation; sixteen patients $(66.7 \%)$ and eight patients $(33.3 \%)$ out of the twenty-four were heterozygotes and homozygotes, respectively. Moreover, two patients out of the total fifty (4\%) experienced FV (G1691A) mutation. Finally, prothrombin mutation (G20210A) has not been detected during the current work (Table 1).

Table 1. The classification of patient included in the current study according to the type of mutation

\begin{tabular}{|c|c|c|c|c|}
\hline Mutation & $\begin{array}{c}\text { Patient's } \\
\text { no. }\end{array}$ & $\begin{array}{c}\text { Percentages } \\
\%\end{array}$ & $\begin{array}{c}\text { Heterozygotes } \\
(\%)\end{array}$ & $\begin{array}{c}\text { Homozygots } \\
(\%)\end{array}$ \\
\hline $\begin{array}{c}\text { MTHFR } \\
\text { (C667T) }\end{array}$ & 24 & 48 & $16(66.7)$ & $8(33.3)$ \\
\hline $\begin{array}{c}\text { FV } \\
\text { (G1691A) }\end{array}$ & 2 & 4 & & \\
\hline $\begin{array}{c}\text { Prothrombin } \\
\text { (G20210A) }\end{array}$ & 0 & 0 & & \\
\hline
\end{tabular}




\section{DISCUSSION}

Thrombosis occurs as an outcome of a deviated function of the blood clotting system. Therefore, it is pivotal to determine the frequencies and risks of the most encountered genetic mutations causing deep vein thrombosis or recurrent pregnancy loss (Elgari et al., 2017).

In recurrent pregnancy loss, there is much debate about cause and association. However, it is important to note that this is not a uniform finding indeed, many studies have been of a small size, prone to stratification and admixture bias, in which there has been poor matching of cases and controls as a result of racial heterogeneity. In addition, publication bias is evident, as judged by the discrepancy between the number of published abstracts reporting a lack of association between genetic thrombophilia and the number of peer reviewed papers reporting an association (Farahmandet al., 2015) .

In line with the results of the current work, it was found that the frequencies and the prevalence of the heterozygous FVL were4 (6.6\%), but when prothrombin G20210A, and MTHFRC677T genotypes were taken into consideration, it was shown that they markedly differ from the outcomes of the present study, as they were recorded in Saudi patients with a prevalence of with RPL were $2(3.3 \%)$, and $3(5 \%)$, respectively (Elgari et al., 2017).Consistently, Kobashiet al., 2005 did not find the FV Leiden mutation in Japanese women with RPL (Kobashiet al., 2005) .Comparable to the results of the present study, it was stated that Tunisian women had higher prevalence of MTHFR 677T/T in late and early-late RPL (Mtiraoui et al., 2006) Moreover, other researchers did not find any association between prothrombin G20210A polymorphism and fetal losses after IVF. (Kutteh et al., 1998) On the other hand, Di Micco et al., (2008) reported that inherited thrombophilia and in particular the prothrombin A20210G variant is relevant risk factor for recurrent pregnancy loss and this observation clearly contradicts the findings of the current study. Furthermore, the similarity is obvious when the result of the current study is generally compared to that of Gonenet al., (2005) and Zahedet al., (2006) who suggested that factor V Leiden is not a predisposing factor for recurrent fetal loss.

The cause of RPL is largely unclear. Epidemiological studies suggested that it might be multifactorial with involvement of environmental and genetic factors (Cramer \& Wise, 2000). Inherited thrombophilia has been implicated as a possible cause (Mierla et al., 2012). Although numerous studies are available in literature, thrombophilia rate seems to vary from study to another due to different selection criteria of the patients (Sarig et al., 2001). Inherited thrombophilia may be due to a gene defect or deficiency of clotting inhibitors leading to a hypercoagulable tendency. Gene defects frequently associated with RPL are prothrombin A20210G and factor V Leiden (Mukhopadhyay et al., 2009). However, these mutations are rare in Asians and thrombophilia investigations are therefore considered irrelevant in these patients. Hence, the status of thrombophilia-induced recurrent pregnancy loss (RPL) in Asian is obscure and poorly understood (Thiruchelvam \& Sekaran, 2010).

\section{CONCLUSION}

It is concluded that different thrombophilic mutations participate in the initiation of RPL either individually or collectively and that these mutations can pose significant potential that threaten the development of normal pregnancy.

\section{REFERENCES}

Al Husseini, N.F.; Odaa, M.M.; Mohamed, M.A.; El Wahab, W.B.A.; Hasan, A.A. (2010). Expression of adiponectin receptors in human placenta and its possible implication in gestational. Am. J. Biochem. Biotechnol., 6, pp.136-40.

Cramer, D.W. \& Wise, L.A., (2000). The Epidemiology of Recurrent Pregnancy Loss.. Seminars in Reproductive Medicine., 18, pp.331-40.

Di Micco, P.; Di Fiore, R.; Niglio, A.; Quaranta, S.; Angiolillo, A. et al. (2008). Different outcome of six homozygotes for prothrombin A20210A gene variant. J. Transl. Med., 6, p.36.

Dong, Y.; Li, L. L.; Wang, R. X. et al. (2014). Reproductive outcomes in recurrent pregnancy loss associated with a parental carrier of chromosome abnormalities or polymorphisms. Genet. Mol. Res. (13): 2849-56.

Elgari, M. M.; Ibrahim, N. A.; Muddathir, A. R. M.; Eltoom, F. M.; Ibrahim, I. M. (2017). Frequency of Thrombophilic Gene Mutations in Patients with Deep Vein Thrombosis and in Women with Recurrent Pregnancy Loss. Open Life Sci., 12, pp.12-166.

Farahmand, K.; Totonchi, M.; Hashemi, M.; ReyhaniSabet, F.; Kalantari, H.; Gourabi, H.; MohseniMeybodi, A. (2015). Thrombophilic genes alterations as risk factor for recurrent pregnancy loss. The journal of maternal-fetal and neonatal medicine. 29(8): 1269-1273.

Gazi, Y.; Ali, Y.; Pınar, Y.; Necdet, S.; Nilgün, T. (2012). Inherited thrombophilia with recurrent pregnancy loss in Turkish women - a real phenomenon? Ginekol. Pol. (83): 598-603.

Gonen, R.; Lavi, N.; Attias, D.; Schliamser, L.; Borochowitz, Z.; Toubi, E.; Ohel, G. (2005). Absence of association of inherited thrombophilia with unexplained third trimester intrauterine fetal death. Am. J. Obstet. Gynecol. 192 (3): 742-746.

Harris, E.N.; Gharavi, A.E.; Boey, M.L.; Patel, B.M.; MackworthYoung, G.G.; Loizou, S. and Hughes, G.R. (1983). Anticardiolipin antibodies: detection by radioimmunoassay and association with thrombosis in systemic lupus erythematosus. Lancet. (11):1211.

Kobashi, G.; Kato, E. H.; Morikawa, M.; Shimada, S.; Ohta, K.; Fujimoto, S. et al (2005). MTHFR C677T Polymorphism and factor $\mathrm{V}$ leiden mutation are not associated with recurrent spontaneous abortion of unexplained etiology in Japanese women.. Semin Thromb. Hemost. , 31(3).

Kujovich, J.L. (2011). Factor V Leiden thrombophilia. Genet. Med. 13: $1-16$.

Kutteh, W.H.; Park, V.M. \& Deitcher, S.R.(1998). Hypercoagulable state mutation analysis in white patients with early firsttrimester recurrent pregnancy loss.. Fertile. Steril.71: 10481053.

López-Jiménez, J.; Porras-Dorantes, Á.;Juárez-Vázquez, C.; GarcíaOrtiz, J.; Fuentes-Chávez, C.; et al. (2016). Molecular thrombophilic profile in Mexican patients with idiopathic recurrent pregnancy loss. Genetics and molecular research. 15(4):

McPherson, E. (2016). Recurrence of stillbirth and second trimester pregnancy loss. American journal of medical genetics. 170A(5): 1174-1180.

Mierla, D.; Szmal, C.; Cretu, R.; Stoian, V.; Jordan, D. (2012). Association of Prothrombin (A20210G) and Factor V Leiden (A506G) with Recurrent Pregnancy Loss. Maedica. $7: 222-26$.

Mtiraoui, N.; Zammiti, W.; Ghazouani, L.; Braham, N. J.; Saidi, S.; Finan, R. R. et al. (2006). MTHFR C677T and A1298C polymorphism and changes in homocysteine concentrations in women with idiopathic recurrent pregnancy losses. Reproduction. 131(2): 395-401.

Mukhopadhyay, R.; Saraswathy, K.N. \& Ghosh, P.K.(2009). MTHFR C677T and Factor V Leiden in Recurrent Pregnancy Loss: A Study among an Endogamous Group in North India. Genetic Testing and Molecular Biomarkers. 13: 861-65.

Neamatzadeh, H.; Ramazani, V.; Kalantar, S. M.; Ebrahimi, M.; Sheikhha, M. H. (2016). Serum immune reactivity against $\beta 2$ Glycoprotein-I and anti-neutrophil cytoplasmic autoantibodies by ELI-P-Complex screening technology in recurrent miscarriage. Minerva ginecologica. 68(3): 243249.

Sah, A. K.; Shrestha, N.; Joshi, P.; Lakha, R.; Shrestha, S.; Sharma, L.; Chandra, A.; et al. (2018). Association of parentalMethylene tetrahydro folatereductase (MTHFR) C677T gene polymorphism in couples with unexplained recurrent pregnancy loss. BMC Res Notes (2018) 11:233. 
Sarig, G., Younis, J.S.; Hoffman, R.; Lanir, N.; Blumenfeld, Z.; Brenner, B. (2001). Thrombophilia Is Common in Women with Idiopathic Pregnancy Loss and Is Associated with Late Pregnancy Wastage. Fertility and Sterility. 77: 342-47.

Thiruchelvam, A and Sekaran, M. (2010). Thrombophilia abnormalities in recurrent pregnancy loss. Biomedical Research. 21 (1): 87-98.
Zahed, L. F.; Rayes, R. F.; Mahfouz, R. A.; Taher, A. T.; Maarouf, H. H.; Nassar, A. H. (2006). Prevalence of factor V Leiden, prothrombin and methylene tetrahydrofolatereductase mutations in women with adverse pregnancy outcomes in Lebanon. Am. J. Obstet. Gynecol. 195: 1114-1118. 